\title{
Induction of DNA Synthesis and Cell Division by Aristeromycin
}

\author{
Masahiro Suno, Kyozo Tsukamoto and Yukio Sugino \\ Biological Research Laboratories, Central Research Division, Takeda Chemical \\ Ind. Ltd., Yodogawa-ku, Osaka 532, Japan
}

\begin{abstract}
Aristeromycin, an antibiotic isolated from Streptomyces citricolor, induced DNA synthesis and cell division of non-dividing 3T3 cells (A-31) in culture. The induction occuried in quiescent cells produced by contact inhibition or by deprivation of serum or isoleucine from culture medium. In confluent culture, the maximum stimulation of DNA synthesis was observed about $24 \mathrm{~h}$ after the addition of aristeromycin and was followed by cell division. The optimum concentration of aristeromycin for induction was about $0.5 \mu \mathrm{g} /$ $\mathrm{ml}$ on glass dishes. In contrast to its stimulative effect on nondividing cells, aristeromycin inhibited growth when added to dividing cells. Growth of other normal cell lines in confluent culture also was induced by aristeromycin. However, growth of malignant cell lines such as SV-3T3, poly-BHK, AC and $\mathrm{KB}$ cells was inhibited. Adenine nucleosides reversed the inductive effect of aristeromycin.
\end{abstract}

Studies with confluent or low density cultures of 3T3 cells indicate that a number of factors can stimulate proliferation of non-dividing cells. Substances such as serum (2), proteolytic enzymes (3), insulin (2), glucocorticoid (19), fibroblast growth factors (4) and epidermal growth factors (10) have been found to initiate the proliferation of non-dividing fibroblastic cells in culture. Recently, certain metal ions (such as $\mathrm{Zn}^{++}$ and $\mathrm{Mg}^{++}$) at subtoxic concentrations have been found to stimulate DNA synthesis and cell proliferation in chick embryo cultures deprived of serum $(12,13)$.

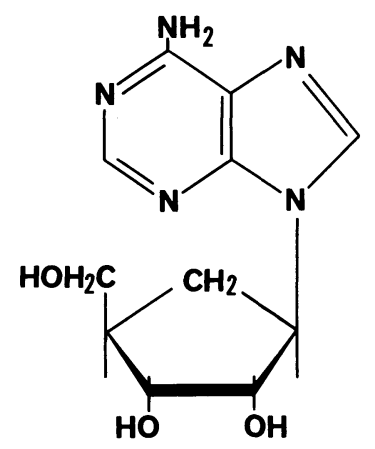

Fig. 1. The structure of aristeromycin 
During our study on the toxicity of various compounds in culture, we found that aristeromycin induced DNA synthesis and cell division in non-dividing cells, and that it inhibited cell growth in dividing cells. Aristeromycin first was synthesized by Shealy and Clayton $(17,18)$, and subsequently was isolated by Kusaka et al. (8) from a culture filtrate of Streptomyces citricolor. This compound is a carbocyclic analog of adenosine, in which the $\mathrm{O}$-atom of the ribofuranosyl ring of the nucleoside is replaced by a methylene group (Fig. 1). We here describe some characteristics of aristeromycin.

\section{MATERIALS AND METHODS}

Cell lines. The clonal line from BALB/C mouse embryo (BALB 3T3, A-31) and the polyoma transfromed BHK cells (poly-BHK) were provided by Dr. A. Hakura (Institute for Microbial Disease, Osaka University, Osaka, Japan). SV-40 transformed 3T3 cells (SV-3T3) were received from Dr. H. Yoshikura (Institute for Medical Science, Tokyo University, Tokyo, Japan). AC is a cell line from rat glioma (7). C-34 is obtained by cloning $\mathrm{C} 3 \mathrm{H} 2 \mathrm{~K}$ (23) derived from newborn $\mathrm{C} 3 \mathrm{H} / \mathrm{He}$ mice. MDBK (from adult bovine kidney) and $\mathrm{KB}$ cells (from human epidermoid carcinoma) were purchased from Flow Laboratories Inc. (Maryland, U.S.A.).

Cell culture. Cells were suspended in Eagle's minimum essential medium (MEM) supplemented with $10 \%$ fetal calf serum (Flow Laboratories Inc.) and $100 \mu \mathrm{g} / \mathrm{ml}$ kanamycin. The suspension of cells was seeded in small petri dishes, each containing a glass coverslip (15 mm in diameter), or in plastic petri dishes $(60 \mathrm{~mm}$ in diameter). To add the testing compound, the medium was aspirated from the dishes and an appropriate medium containing the testing compound was added. Arrested cells in sparse culture were prepared by cultivating cells in isoleucine deficient medium according to the method of Tobey (20).

Cell counts. Cells grown on glass coverslips were measured as follows. A coverslip was placed in a sample tube containing $1 \mathrm{ml}$ of a calcium- and magnesium-free balanced solution with $0.125 \%$ trypsin and $0.01 \%$ ethylenediaminetetraacetate. After standing for about $5 \mathrm{~min}$ at room temperature, $9 \mathrm{ml}$ of Isoton (a diluent made by Coulter Diagnostics Inc. U.S.A.) was added to the tube. The contents of the sample tube were pipetted about 50 times to disperse the cells. Cells were counted with a Coulter Counter (Model ZB with $100 \mu$ m aperture tube). Points on the figures are the mean values calculated for two to three coverslips.

Assay of DNA synthesis. The DNA synthesis induced by aristeromycin was estimated by measuring the radioactivity of $\left[{ }^{32}\right.$ p]incorporated into the DNA fraction of the cells, instead of the amount of $\left[{ }^{3} \mathrm{H}\right]$ thymidine incorporated, because aristeromycin is an analog of the nucleoside and the incorporation of $\left[{ }^{3} \mathrm{H}\right]$ thymidine did not reflect true DNA synthesis (data not shown). Fractionation was performed by the method of Schmidt-Thanhauser-Schneider (15) with some modifications. After labelling cells with $\left[{ }^{32} \mathrm{p}\right]$ for $30 \mathrm{~min}$ or $24 \mathrm{~h}$ (final concentration 5-10 $\mu \mathrm{Ci} / \mathrm{ml}$ ), the cell layers were washed with MEM without serum then the cells were harvested with a rubber policeman. The cell suspension was centrifuged, after which the sediment was washed twice with MEM without serum. Two milliliters of cold perchloric acid $(4 \%)$ were added to the sediment, which was then allowed to stand for $10 \mathrm{~min}$ in crushed ice before being centrifuged. The same procedure was repeated twice for each sediment. After the sediment had been washed with $2 \mathrm{ml}$ of methanol, $2 \mathrm{ml}$ of a mixture of methanolchloroform ( $1: 1)$ was added, and the entire mixture was heated at $80-\mathrm{C}$ for 3 min then centrifuged. The resulting sediment was dispersed in $1 \mathrm{ml}$ of $0.3 \mathrm{~N} \mathrm{KOH}$, after which the mixture was incubated at $37-\mathrm{C}$ for $16 \mathrm{~h}$. It was then cooled in an ice-bath and $60 \%$ perchloric 
acid was added to it to make a $4 \%$ final concentration. After the sample had been left for $10 \mathrm{~min}$, the precipitate was obtained by centrifugation. It was washed twice with $2 \mathrm{ml}$ of cold $4 \%$ perchloric acid. One milliliter of $4 \%$ perchloric acid was added to the washed precipitate, which contained DNA, and the sample was heated at $90-\mathrm{C}$ for $15 \mathrm{~min}$. After centrifugation, aliquots of the supernatant were used for the radioactivity measurement.

Chemicals. Aristeromycin was the gift of Dr. Y. Kishi (Microbiological Research Laboratories in our division). Nucleosides were purchased from Wako Pure Chemical Ind. Ltd., (Osaka, Japan). [ ${ }^{32}$ p] was obtained from the Japan Atomic Energy Research Institute.

\section{RESULTS}

Effects of aristeromycin on DNA synthesis and cell division in confluent culture. When $5 \times 10^{5} 3 \mathrm{~T} 3$ cells had been seeded on a $60 \mathrm{~mm}$ plastic dish and incubated for 3 days, the cells were in a state of density-inhibition or quiescence. These quiescent $3 \mathrm{~T} 3$ cells were cultured in medium containing $2 \%$ serum and aristeromycin $(2 \mu \mathrm{g} / \mathrm{ml})$. The serum concentration of $2 \%$ was used to maintain the control culture in a nondividing state with minimum cell death. However, even at this concentration of serum, some cells floated and amount of cells on the substratum of the dish decreased during cultivation (Fig. 2).

After a lag period of about $8 \mathrm{~h}$, an increase in the rate of DNA synthesis was observed in cultures treated with aristeromycin. The rate of DNA synthesis reached a maximum about $24 \mathrm{~h}$ after the addition of aristeromycin and cell division was observed $48 \mathrm{~h}$ after this addition (Fig. 2). The number of cells in the treated cultures increased about 2-fold as compared with the control cultures. Even though the medium was changed daily with fresh medium containing aristeromycin, the cell numbers did not increase more than 2-fold.

The optimum concentration of aristeromycin that induced DNA synthesis and cell division was about $2 \mu \mathrm{g} / \mathrm{ml}$ in a plastic dish (Figs. 3 and 4). For a glass coverslip, the optimum concentration for cell division shifted to $0.5 \mu \mathrm{g} / \mathrm{ml}$ (Fig. 3). The optimum concentration for DNA synthesis on the glass coverslip was not determined, since in

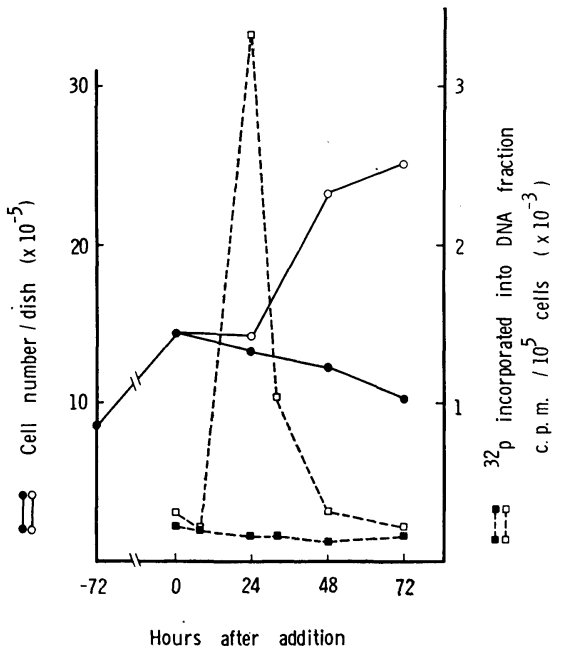

Fig. 2. Time courses of the initiation of DNA synthesis and cell division by aristeromycin in confluent culture. A suspension of $5 \times 10^{5} 3 \mathrm{~T} 3$ cells was seeded in a $60 \mathrm{~nm}$ plastic petri dish in medium wiht $10 \%$ serum. Three days later, the medium was replaced with one containing $2 \mu \mathrm{g} / \mathrm{ml}$ of aristeromycin and $2 \%$ serum. The radioactivity incorporated into the DNA fraction in cultures with

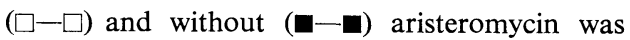
measured after pulse-labeling with $\left[{ }^{32} \mathrm{p}\right]$ for 30 min. Cell numbers in cultures with $(\bigcirc-\bigcirc)$ and without (-) aristeromycin were measured daily. 


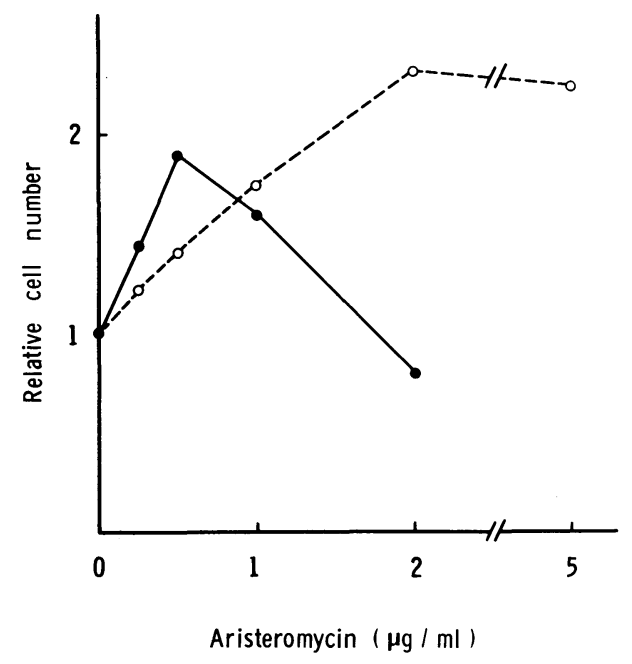

Fig. 3.

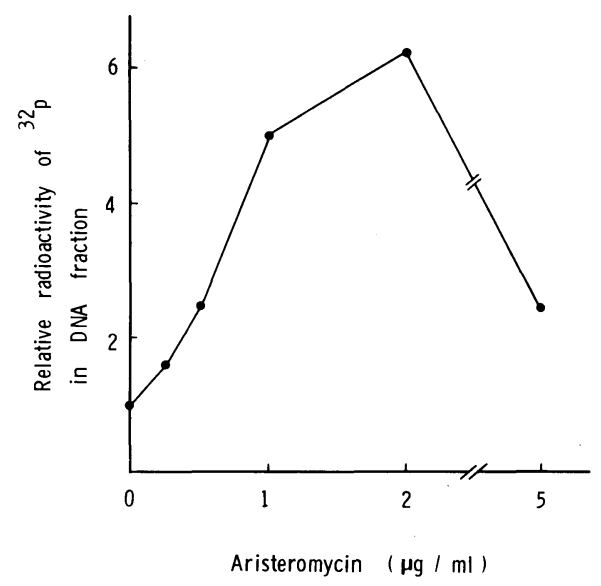

Fig. 4.

Fig. 3. Effects of various concentrations of aristeromycin on cell growth in confluent culture. $3 \mathrm{~T} 3$ cells, at a concentration of $10^{5}$ cells $/ \mathrm{ml}$ in a medium with $10 \%$ serum, were seeded in glass (-) or plastic dish $(\bigcirc-\bigcirc)$ then cultured for 3 days. The medium was replaced with one containing various concentrations of aristeromycin, and the cells were cultured for an additional 3 days in medium with $2 \%$ serum. Cell numbers were measured 3 days after the addition of aristeromycin. The number of cells in the control culture, without aristeromycin, was $1.4 \times 10^{6}$ cells $/(60 \mathrm{~mm}$ plastic dish) and $1.3 \times 10^{5}$ cells/(15 mm glass coverslip).

Fig. 4. Effects of various concentrations of aristeromycin on DNA synthesis in confluent culture. Culture conditions were the same as those described in fig. $2 .\left[{ }^{32} \mathrm{p}\right]$ was added along with aristeromycin. Cells were harvested $24 \mathrm{~h}$ after the addition. The DNA fraction was isolated, and its radioactivity was measured (see materials and methods for detail).

our coverslip system the numbers of cells were not sufficient to measure DNA synthesis by ${ }^{32}$ p]incorporation. However, the results obtained for plastic dishes indicated that the optimum concentration for DNA synthesis on glass coverslips might be a lower concentration than that for the plastic dish. More than $2 \mu \mathrm{g} / \mathrm{ml}$ of the antibiotic in glass coverslip caused extensive cell damage and destroyed the cell sheet. The morphology of the cells at the optimum concentration resembled that of transformed cells; they were piled up and aligned in randam array. In the following experiments on cell growth, glass coverslips were used for the convenience of counting cell numbers.

Effects of aristeromycin on cell growth in sparse culture. Cells were seeded at concentration of $5 \times 10^{4}$ in dishes containing a $15 \mathrm{~mm}$ glass coverslip. Medium with $10 \%$ serum was added and the dishes were cultured. Twenty-four hours after the seeding, various concentrations of aristeromycin were added to the culture. In contrast to the case of non-dividing cells (Figs. 2 and 3), cell growth was inhibited at all the concentrations of aristeromycin tested (Fig. 5). A concentration of more than $0.5 \mu \mathrm{g} / \mathrm{ml}$ damaged the cells, and most floated. The concentration giving $50 \%$ inhibition of growth was about $0.2 \mu \mathrm{g} / \mathrm{ml}$.

When aristeromycin was added to arrested cells that had been produced by cultivation in medium with $0.5 \%$ serum for 2 days, the induction of cell growth was observed (Fig. 5). The optimum concentration for this induction was about 0.25 


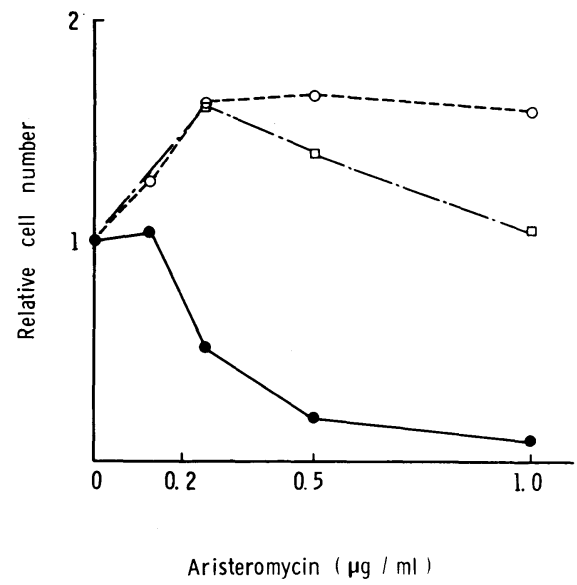

Fig. 5. Effects of various concentrations of aristeromycin on growing and arrested cells in sparse culture. A suspension of $5 \times 10^{4} 3 \mathrm{~T} 3$ cells was seeded in a dish containing a glass coverslip in medium with $10 \%$ serum. In the growing culture $(-\bullet)$, the medium was replaced with one containing different concentrations of aristeromycin one day after seeding. In the arrested culture, the medium was replaced with one with $0.5 \%$ serum $(\bigcirc-\bigcirc)$ or with an isoleucine deficient medium $(\square-\square)$ one day after seeding, then the cells were cultured for 2 days to arrest growth. After the addition of aristeromycin, cells were grown in medium with $2 \%$ serum. In both cases, the number of cells was measured 3 days after the addition of aristeromycin. The number of cells on the $15 \mathrm{~mm}$ glass coverslip in the control culture was $3.1 \times 10^{5}$ (growing), $9.6 \times 10^{4}$ (arrested by serum deprivation), and 9.5 $\times 10^{4}$ cells (arrested by isoleucine deprivation).

$\mu \mathrm{g} / \mathrm{ml}$. To confirm the stimulating effect of aristeromycin on non-dividing cells in a sparse culture, we used an isoleucine deficient medium instead of serum deprivation to arrest cell division. Induction also was observed under this condition (Fig. 5). The extent of induction at a concentration of $0.25 \mu \mathrm{g} / \mathrm{ml}$ was comparable to that of

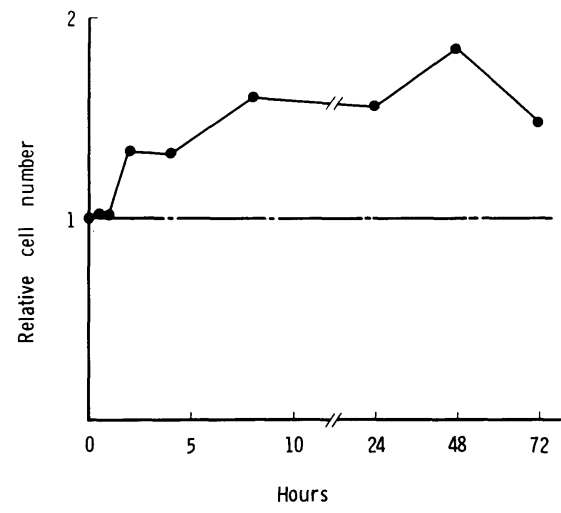

Fig. 6.

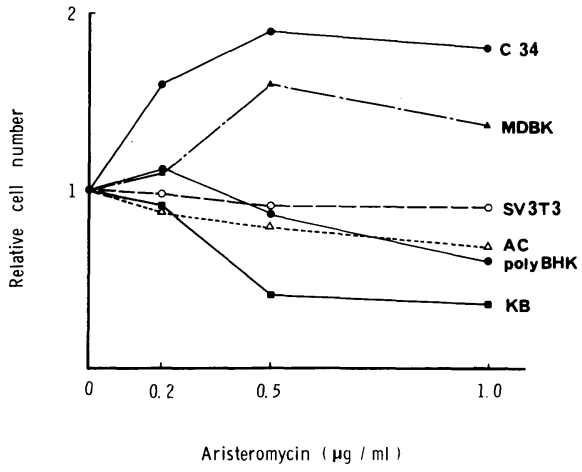

Fig. 7.

Fig. 6. Minimum periods of exposure to aristeromycin necessary to induce cell growth in confluent culture. Culture conditions were the same as in fig. 2. At various times after exposure to aristeromycin, the medium was aspirated, and cells were washed twice with fresh medium without aristeromycin. The number of cells was measured 3 days after the addition of aristeromycin.

Fig. 7. Effects of aristeromycin on the growth of various cell lines. Procedures were the same as those for the glass coverslip in fig. 3 except that various cell lines were used. 


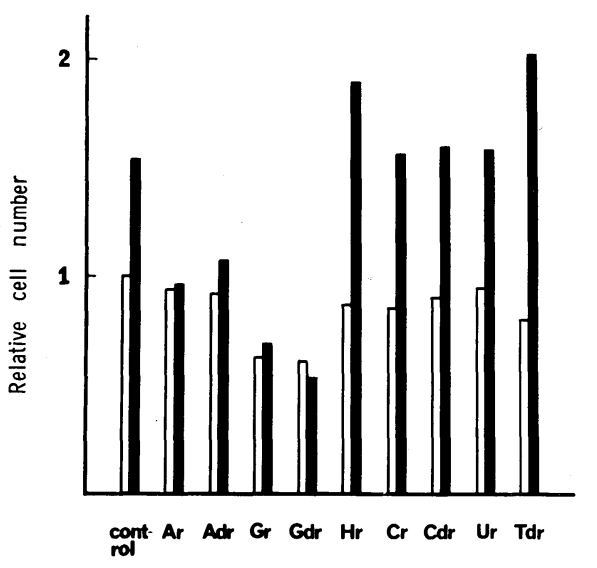

Fig. 8. Effects of nucleosides on the cell growth induced by aristeromycin in confluent culture. Culture conditions were the same as those for the glass coverslip in fig. 3 . Three days after seeding the cells, the medium was replaced with one containing aristeromycin $(0.5 \mu \mathrm{g} / \mathrm{ml}, 2 \mu \mathrm{M})$ plus various nucleosides in $2 \%$ serum. White bars represent nucleosides; black bars aristeromycin plus nucleosides. Ar, adenosine; Adr, deoxyadenosine; $\mathrm{Gr}$, guanosine; Gdr, deoxyguanosine; Hr, hypoxanthine riboside; $\mathrm{Cr}$, cytidine; $\mathrm{Cdr}$, deoxycytidine; $\mathrm{Ur}$, uridine; $\mathrm{Tdr}$, thymidine. The number of cells in the control culture was $1.6 \times 10^{5}$ cells $/(15$ mm glass coverslip).

serum deprivation. However, some inhibition was observed at higher concentrations of aristeromycin.

The minimum period of exposure to aristeromycin necessary to induce cell growth. At various times after exposure of confluent 3T3 cells to aristeromycin, the medium was changed to a fresh one with $2 \%$ serum without aristeromycin; cell numbers were counted 3 days after the addition of the compound. Results are shown in Fig. 6. Exposure of 3T3 cells to aristeromycin for at least $2 \mathrm{~h}$ was required to induce the cell growth.

Effect of aristeromycin on cell growth in various cell lines. Various cell lines were tested in confluent culture. Results are shown in Fig. 7. Growth of normal cell lines, such as fibroblastic C-34 cells and epithelial MDBK cells, was induced by aristeromycin at a concentration of $0.5 \mu \mathrm{g} / \mathrm{ml}$. No induction of growth was observed in malignant cell lines such as SV-3T3, poly-BHK, AC and KB cells. These cell lines all were inhibited at concentrations higher than $0.5 \mu \mathrm{g} / \mathrm{ml}$.

Effects of nucleosides on the growth induced by aristeromycin. Since aristeromycin is an analog of adenosine, its effect on cells may ascribed to nucleoside metabolism. Experiments were performed to examine whether nucleosides reversed the stimulative effect of aristeromycin on cell growth in confluent cells (Fig. 8). The nucleosides used were at $100 \mu \mathrm{M}$, because at concentration higher than $100 \mu \mathrm{M}$ these nucleosides were toxic to $3 \mathrm{~T} 3$ cells. The results indicated that adenosine and deoxyadenosine reversed the initiation of cell growth by aristeromycin $(0.5 \mu \mathrm{g} / \mathrm{ml}, 2 \mu \mathrm{M})$. Guanosine and deoxyguanosine also reversed the effect of aristeromycin. However, these nucleosides at the concentration of $100 \mu \mathrm{M}$ also inhibited the growth of untreated control cells. Lower concentrations of these guanine nucleosides had no effect on cell growth. Hypoxanthine riboside and thymidine stimulated the growth induced by aristeromycin (Fig. 8).

\section{DISCUSSION}

These studies demonstrate that aristeromycin induces DNA synthesis and cell division in non-dividing 3T3 fibrobrast cells (A-31). It is noteworthy that the compound has quite different effects, depending on the phase of cell growth. It acts as a growth-stimulating agent on non-dividing, quiescent cells and as growth-inhibitory 
agent on growing cells.

Purine nucleosides such as adenosine and inosine have been reported to enhance DNA synthesis in quiescent 3 T3 cells induced by a serum factor (16); in addition, 6,8-dihydropurine promotes the growth of a hamster cell line (22). Recently, a purine nucleotide, diadenosine $5^{\prime}, 5^{\prime \prime \prime}-\mathrm{p}^{1}, \mathrm{p}^{4}$-tetraphosphate $\left(\mathrm{Ap}_{4} \mathrm{~A}\right)$, has been discovered in mammalian cells (9). $\mathrm{Ap}_{4} \mathrm{~A}$ stimulates the initiation of DNA synthesis in baby hamster kidney cells that have been arrested in the $G_{1}$ phase by the deprival of serum (5).

These results indicate that purine or purine nucleosides have a growth-regulation function. Our present study has shown that the initiation of cell growth by aristeromycin is reversed by adenine nucleosides. Our results indicate that aristeromycin exerts its effects by modulating the metabolism of adenosine. Guanine nucleosides also reversed the effects of aristeromycin, but it is uncertain whether these nucleosides have the same effect as adenosine, because by themselves they inhibited the growth induced by aristeromycine as well as the growth of control cells. Whether hypoxanthine riboside and thymidine stimulated the cell growth induced by aristeromycin is no clear. Bennett et al. (1) have shown that aristeromycin inhibited an early step of de novo purine biosynthesis in culture. This agrees with our result that the effect of aristeromycin was reversed by adenosine. However, if aristeromycin inhibits purine biosynthesis, the intracellular purine nucleoside pool would be deficient. This conflicts with the finding that purine nucleosides have growth promoting activity (16).

Various substances have been reported to induce DNA synthesis and cell growth. Although the mechanism(s) for this have not been determined, the cell membrane has been proposed as the primary site of action for serum factors (6), viral transformation (11) and stimulation by other factors (21). Recently, Rubin and Koide (13) and Rubine (12) reported that DNA synthesis in serum-deprived chick embryo culture was stimulated by a subtoxic concentration of certain metal ions and by a carcinogenic hydrocarbon. They proposed that these substances also act on the cell surface primarily because metals are known to bind tightly to membranes and carcinogenic hydrocarbons have high affinities for the lipoidal portions of cells.

Aristeromycin resembles metal ions and carcinogenic hydrocarbon in that it induces cell proliferation of quiescent cells at subtoxic concentrations. However, it is unlikely that the primary action of aristeromycin is on the cell membrane because it can permeate the cell membrane and is converted to $5^{\prime}$-mono, di- and tri-phosphate froms inside the cell (1).

Cells treated with aristeromycin increased 2-fold as compared with control cultures, but they did not increase more than 2-fold. This indicates that aristeromycin is able to initiate one round of cell division in the cell cycle. Bombik and Burger (2) have shown that agents like serum, proteolytic enzymes and insulin, all of which can initiate one round of cell division in arrested fibroblast cultures, lowered cyclic AMP levels. They suggest that the decrease in intracellular cyclic AMP may trigger growth in confluent and resting cultures. The possibility that aristeromycin acts as an agent that changes the intracellular level of cyclic AMP needs to be investigated.

Acknowledgments. We wish to thank Dr. J. R. Miller and Dr. H. Iwatsuka for their suggestions on the preparation of this manuscript. 


\section{REFERENCES}

1. Bennett, Jr. L. L., P. W. Allan and D. L. Hill. Metabolic studies with carbocyclic analogs of purine nucleosides. Mol. Pharmacol., 4, 208-217, 1968

2. Bombik, B. M. and M. M. Burger. cAMP and the cell cycle: initiation of growth stimulation. Exptl. Cell Res. 80, 88-94, 1973

3. Burger, M. M. Proteolytic enzymes initiating cell division and escape from contact inhibition of growth. Nature 227, 170-171, 1970

4. Gospodarowicz, D. Localisation of a fibroblast growth factor and its effect alone and with hydrocortison on 3T3 cell grwoth. Nature 249, 123-127, 1974

5. Gurummt, F. Diadenosine $5^{\prime}, 5^{\prime \prime \prime}-\mathrm{p}^{1}, \mathrm{p}^{4}$-tetraphosphate triggers initiation of in vitro DNA replication in baby kidney cells. Proc. Natl. Acad. Sci. U.S.A. 75, 371-375, 1978

6. Holly, R. Unifying hypothesis concerning the nature of cancer. Proc. Natl. Acad. Sci. U.S.A. 69, 2840-2841, 1972

7. Igarashi, K., S. Ikeyama, M. Takeuchi and Y. Sugino. Morphological changes in rat glioma cells caused by adenosine cyclic 3', 5'-monophosphate. Cell Struc. Func. 3, 103-112. 1978

8. Kusaka, T., H. Yamamoto, M. Shibata, M. Muroi, Y. Kishi and K. Mizuno. Streptomyces citricolor Nov. Sp. and a new antibiotics, aristeromycin. J. Antibiotics (Tokyo) .21, 255-263. 1968

9. Rapaport, E., P. C. ZAMECNIK. Presence of diadenosine $5^{\prime}, 5^{\prime \prime \prime}-\mathrm{P}^{1}, \mathrm{P}^{4}$-tetraphosphate (Ap 4 A) in mammalian cells in levels varying widely with proliferative activity of the tissue: a possible positive "pleotypic activator". Proc. Natl. Acad. Sci. U.S.A. 73, 3984-3988, 1976

10. Rose, S. P., R. M. Pruss and H. R. Hershman. Initiation of 3T3 fibroblast cell division by epidermal growth factor. J. Cell Physiol. 86, 593-598, 1975

11. Rubin, H. Growth regulation in cultures of chick embryo fibroblasts. Ciba foundation Symposium on Growth Control in Cell Cultures. Churchill, Livingstone, Edinburgh, pp. 129-149, 1971

12. RubIN, H. Nonspecific nature of the stimulus to DNA synthesis in cultures of chick embryo cells. Proc. Natl. Acad. Sci. U.S.A. 72, 1676-1680, 1975

13. Rubin, H., T. Koide. Stimulation of DNA synthesis and 2-deoxy-d-glucose transport in chick embryo culture by excessive metal concentrations and by a carcinogenic hydrocarbon. J. Cell Physiol. 81, 387-396, 1973

14. SAmbrook, J. Transformation by polyoma virus and simian virus 40. in Advances in Cancer Research. G. Klein, S. Weinhouse, eds. Academic Press, New York and London, pp. 141-180, 1972

15. Schneider, W. C. Phosphorus compounds in animal tissue. III. A comparison of method for the estimation of nucleic acids. J. Biol. Chem. 164, 747-751, 1946

16. SCHOR, S. and E. Rozengurt. Enhancement by purine nucleosides and nucleotides of seruminduced DNA synthesis in quiescent 3T3 cells. J. Cell Physiol. 81, 339-436, 1973

17. Shealy, Y. F. and J. D. Clayton. 9-[ $\beta$-DL-2 $\alpha, 3 a$-dihydroxy-4 $\beta$-(hydroxymethyl)-cyclopentyl] adenosine, the carbocyclic analog of adenosine. J. Am. Chem. Soc. 88, 3885-3887, 1966

18. Shealy, Y. F. and J. D. Clayton. Synthesis of carbocyclic analogs of purine ribonucleosides. J. Am. Chem. Soc. 91, 3075-3085, 1969

19. Thrash, C. R. and D. D. Cunningham. Stimulation of division of density inhibited fibroblasts by glucocorticoids. Nature 242, 399-401 1973

20. ToBey, R. A. Production and characterization of mammalian cells reversibly arrested in $\mathrm{G}_{1}$ by growth in isoleucine-deficient medium. in Methods in Cell Biology, D. M. Prescott, ed., Academic Press, New York and London. pp. 67-112, 1973

21. Vesiliev, J., I. Gelfand, V. Guelstein and E. Fetisova. Stimulation of DNA synthesis in cultures of mouse embryo fibroblast-like cells. J. Cell Physiol. 75, 305-313, 1970

22. Yamane, I. and O. Murakami. 6,8-dihydroxypurine: a novel growth factor for mammalian cells in vitro, isolated from a commercial peptone. J. Cell Physiol. 81, 281-284, 1973

23. Yoshikura, H., Y. Hirokawa and M. Yamada. Synchronized cell division induced by medium change. Exp. cell Res. 48, 226-228, 1967 